\title{
Hemorrhagic Ascites
}

National Cancer Institute

\section{Source}

National Cancer Institute. Hemorrhagic Ascites. NCI Thesaurus. Code C36063.

Accumulation of hemorrhagic fluid in the peritoneal cavity. 